\title{
Synthesis of Nanofiber from Poly Vinyl Alcohol (PVA)-Collagen using Electrospinning Methods
}

\section{Sudirman $^{1 *}$, Aloma Karo Karo ${ }^{1}$, Sulistioso Giat Sukaryo ${ }^{1}$, Karina Dwi Adistiana ${ }^{2}$, and Kiagus Dahlan ${ }^{2}$}

1) The Center for Science and Texchnology Advanced Material, National Nuclear Energy Agency of Indonesia, Kawasan Puspiptek, South Tangerang 15314, Indonesia

2) Department of Physics, IPB University, Jl. Meranti, Kampus IPB Dramaga, Bogor 16680, Indonesia

*Corresponding author : sudirman@batan.go.id

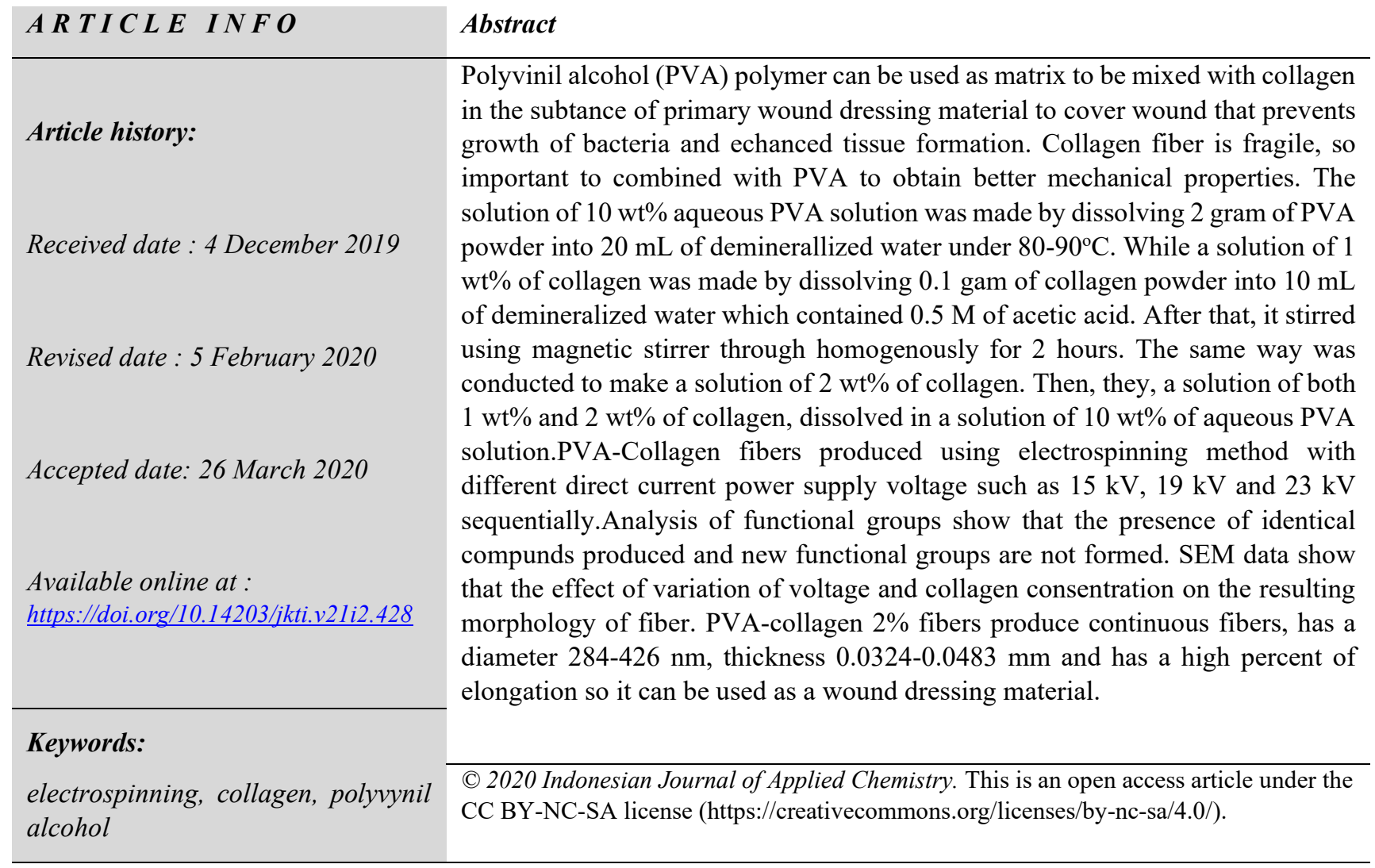

\section{INTRODUCTION}

Over the past few decades, the development of nanotechnology has grown very rapidly and has an impact on developments in various industries. One of the materials produced using the principle of nanotechnology is nanofiber. Nanofiber has advantages such as high surface 
area, porous structure, elastic and can be applied effectively to the medical field, filtration, wound dressing and others [1].

Manufacturing nanofiber can be conducted with several methods, one of which is the electric spinning method. Electric spinning is a method for making micro-sized fibers up to nanometers. The results of electric spinning have the advantage of being able to produce fibers that are long enough and uniform. Electric spinning fiber results can be applied in biomedical fields such as wound dressing materials [2]. Various types of nanofiber can be produced from various types of polymers both natural polymers and synthetic polymers. One of the natural polymer materials used is collagen. Collagen is a connective tissue protein used as an additive in the medical, pharmaceutical, food and cosmetic industries. Collagen has biocompatible properties in the body, non-toxic, and easily absorbed. In addition, collagen can be useful in the medical field to accelerate the growth of new tissue [3].

Collagen has a biological function in the formation of tissues and organs. It is also involved in cell division, defense and differentiation. The possessed characteristics of collagen are easily absorb in the body, low antigenicity, low affinity with water, non-toxic, biocompatible, relatively stable, easilty served in the different formation and high solubility in water and acid [4].

Manufacturing nanofiber from natural polymer solution such as collagen is not possible because of its mechanical properties has many deficiencies compared to synthetic polymers, making it difficult to be processed using electric spinning. Therefore, the natural polymer solution of collagen should be mixed with synthetic polymers one of them polyvinyl alcohol (PVA) [5]. Polyvinyl alcohol (PVA) is a synthetic resin used as a support material for tissue engineering because it has stable, flexible, non-toxic, non-carciogenic, and elastic mechanical properties [6]. PVA is kind of additive which has high tensile strength and flexibility, good thin film forming and good adhesive - that can glue collagen powder to solid membrane. In the formation of membrane, the addition of this additive is to improve its basic properties so that it provides many benefits and uses. The mechanical properties of membrane will be stronger and resiliance [7]. According to aforementioned reason, the research on the synthesis of fiber-based composite PVAcollagen using electric spinning method can be applied as a wound dressing material.

Electrospinning can be influenced by several parameters including solution, process and enviromental parameters. Solution parameters include concentration, molecular weight, viscosity, surface tension, conductivity or surface charge density. Meanwhile, the process parameters include applied voltage, feed rate or flow rate, type of collector and distance of collector tip. While enviromental parameters include humidity and temperature [8].

The sample characterization involves the Fourier Transform Infra-Red (FT-IR) test to determine the functional fiber group, Scanning Electron Microscope (SEM) test to determine the diameter, morphology and fiber structure, X-Ray Diffraction (XRD) test to find out the phase structure of fiber and test drag to know the mechanical strength of the resulting fiber.

\section{EXPERIMENTAL}

\subsection{Synthesis of Polyvynil Alcohol Solution (PVA)}

A $10 \%$ concentration of PVA was prepared by dissolving 2 grams of PVA powder into 20 $\mathrm{mL}$ demineralized water at $80-90^{\circ} \mathrm{C}$ and stirring using a magnetic stirrer for approximately 2 hours until homogeneous solution. 
pp. $55-65$, April 2020

\subsection{Synthesis of Collagen Solution}

Collagen solution was made into two concentrations of $1 \%$ and $2 \%$. A $1 \%$ collagen solution is prepared by dissolving 0.1 gram of collagen powder into $10 \mathrm{~mL}$ of demineralized water containing $0.5 \mathrm{M}$ acetic acid and stirring using a magnetic stirrer for about 2 hours until homogeneous solution. A 2\% collagen solution was prepared by dissolving 0.2 grams of collagen powder into $10 \mathrm{~mL}$ of demineralized water containing $0.5 \mathrm{M}$ acetic acid and stirring using a magnetic stirrer for approximately 2 hours until homogeneous solution.

\subsection{Synthesis of PVA-Collagen Solution}

The PVA-collagen solution was made into 2 ie $1 \%$ collagen solution dissolved into $10 \%$ PVA solution and $2 \%$ collagen solution dissolved into $10 \%$ PVA solution. The PVA-collagen solution was prepared by mixing homogeneous collagen solution into the PVA solution, pouring the collagen solution slowly and stirring using a magnetic stirrer for about3 hours until both homogeneous solutions.

\subsection{Synthesis PVA-Collagen Fibers}

PVA-collagen fibersweremade by using electric spinning method. A homogeneous PVAcollagen solution was inserted into a tube equipped with a syringe. Then the needle was connected to a positive voltage source while the low voltage source (ground) connected to the collector wire as the fiber container produced by the electric spinning apparatus. The distance from the tip of the syringe to the collector wire was $10 \mathrm{~cm}$. After that the PVA-collagen solution was passed through a spinneret (jet) hole with a diameter of $0.6 \mathrm{~mm}$ with a spraying rate at the pump of $0.5 \mathrm{~mL} / \mathrm{hr}$. Then the PVA-collagen fibers produced using direct current power supply voltage such as $15 \mathrm{kV}, 19 \mathrm{kV}$ and $23 \mathrm{kV}$ sequentially. And then the fibers were accommodated on the collector wire. High voltage has a great effect in producing good fiber. It created a strong electric field to draw the surface of the solution at the tip of needle during the spinning process [9].

\subsection{Characterization of PVA-Collagen Fibers}

\subsubsection{Determination functional garoup using} FourierTransform Infrared Spectroscopy (FT$I R)$

The characterization using FT-IR was performed to determine the functional groups in collagen, PVA and collagen-PVA fibers. First of all, the sample was inserted into the sample container. $\mathrm{KBr}$ used to eliminate background on the FT-IR spectrum. The test results are shown in graphical form that stated the relationship of wave numbers with the percent of transmittance. The functional group analysis of the sample was performed by comparing the absorbance bands formed on the infrared spectrum. The resulting spectrum FT-IR will have a range of wave numbers $400-4000 \mathrm{~cm}^{-1}$.

\subsubsection{Determination of surface fiber morphology using Scacning Electron Microscope (SEM)}

Fibers sample which will be tested were placed on an aluminum plate then observed using SEM at 2000 magnification times. Characterization of SEM was performed to determine surface morphology and PVAcollagen fiber diameter. Fiber size can be known using imageJ software by using 10 points of fiber in diameter measured, then made on average.

\subsubsection{Analysis of fase structure using X-ray Diffraction}

Characterization of XRD was performed to identify the phase, lattice parameters, and degree

\footnotetext{
"Synthesis of Nanofiber from Poly Vinil Alcohol (PVA) Collagen ...": Sudirman, et.al. | 57
} 
of crystallinity of sample. The tested sample was given X-rays at an angle of $2 \theta$ from $5^{\circ}$ to $60^{\circ}$. After that it compacted and leveled on the available holder. The XRD tool used is PANalalytical Empyrean Philips Cu-K-alpha radiation source with a wavelength of 1,54060 $\AA$.

\subsubsection{Determination of thickness fibers}

The fiber was measured in thickness by using a screw micrometer with a precision of 0.001 $\mathrm{mm}$. The average thickness was measured from 10 repetitions at different positions. The measurement results are expressed in $\mathrm{mm}$.

\subsubsection{Determination of the mechanical properties of fibers}

The determination of the mechanical properties of the fibers was carried out using a Universal Testing Machine (UTM) strograph VGS S-E Toyoseiki based on American Standard Testing and Material (ASTM) D1822L. This test aims to determine the mechanical properties such as strength, elasticity, stiffness and plasticity.

\section{RESULT AND DISCUSSION}

\subsection{Analysis of Functional Group}

The result of collagen functional group analysis (Figure 1, grafic of red) found three main groups, namely amide group A, amide I, and amide II. The area of amide A located at wave number of $3367.71 \mathrm{~cm}^{-1}$ indicating the presence of N-H stretching as well as indicating the presence of hydrogen bond. The amide group A has a wave number in the absorption range of $3300-3440 \mathrm{~cm}^{-1}[6]$. The area of amide I found in the wave number of $1647.21 \mathrm{~cm}^{-1}$. The amide group I denotes the presence of $\mathrm{C}=\mathrm{O}$ stretching which shows the structure of the secondary proteins. The amide group I has an absorption region in the range of 1625-1690 $\mathrm{cm}^{-1}$ [7]. The spectrum of the amide group II lies in the wave number $1544.98 \mathrm{~cm}^{-1}$. The area of amide II shows the presence of vibrations of $\mathrm{CH}_{2}$ bending and $\mathrm{C}-\mathrm{N}$ stretching. The amide II group lies in an absorption region of $1480-1575 \mathrm{~cm}^{-1}$. The main spectrum of collagen is the vibration of strain in amide I which arises from the vibration of strain $\mathrm{C}=\mathrm{O}$.

The result of PVA function group analysis (Figure 1, grafic of blue) shows that PVA has an absorption region at length of wave number $3200-3600 \mathrm{~cm}^{-1}$, the absorption peak at wave number $3446.79 \mathrm{~cm}^{-1}$ is an $\mathrm{O}-\mathrm{H}$ bending and stretching group. The stretching $\mathrm{C}-\mathrm{H}$ group lies in the $2900-3000 \mathrm{~cm}^{-1}$ absorption region and the peak is detected at the wave number $2924.09 \mathrm{~cm}^{-}$ 1. The $\mathrm{C}=\mathrm{C}$ group is detected at the top with a wave number of $1631.76 \mathrm{~cm}^{-1}$ with an absorption area of $1627-1680 \mathrm{~cm}^{-1}$. The C-O stretching group is detected at the peak with the wave number $1035.77 \mathrm{~cm}^{-1}$ and the absorption region at wave number $1225-950 \mathrm{~cm}^{-1}$ [12].

Figure 1 (green spectra and violet spectra) are spectrum of PVA-collagen $1 \% \mathrm{wt}$ fiber and PVA-collagen $2 \%$ wt fibers by electric spinning process, respectively. Absorption analysis results of $1 \%$ PVA-collagen fibers (Figure1, green spectra) showed the presence of the $\mathrm{O}-\mathrm{H}$ stretching and $\mathrm{N}-\mathrm{H}$ stretching function groups at wave numbers of $3429.43 \mathrm{~cm}^{-1}$. C-H stretching group lies in wave number $2922.16 \mathrm{~cm}^{-1}$. Cluster $\mathrm{C}=\mathrm{C}$ stretching and $\mathrm{C}=\mathrm{O}$ at wave number $1637.56 \mathrm{~cm}^{-1}$. C-O stretching group lies in wave number $1099.43 \mathrm{~cm}-1$. The results of the absorption analysis of 2\% PVA-collagen fibers (Figure1, violet spectra) showed the presence of $\mathrm{O}-\mathrm{H}$ stretching and N-H stretching function groups at $3439.08 \mathrm{~cm}^{-1}$ wave numbers. $\mathrm{C}-\mathrm{H}$ stretching group lies in wave number $2922.16 \mathrm{~cm}^{-1}$. Cluster $\mathrm{C}=\mathrm{C}$ stretching and $\mathrm{C}=\mathrm{O}$ at wave number $1637.56 \mathrm{~cm}^{-1}$. C-O stretching group lies in wave number $1120.64 \mathrm{~cm}^{-1}$. The 
value of the wave numbers in the functional groups formed increases with the concentration of the collagen solution. The resulting PVAcollagen fibers produce an infrared absorption region that is not much different from PVA and collagen. This indicates the presence of identical compounds that are formed and does not result in the formation of new functional groups.

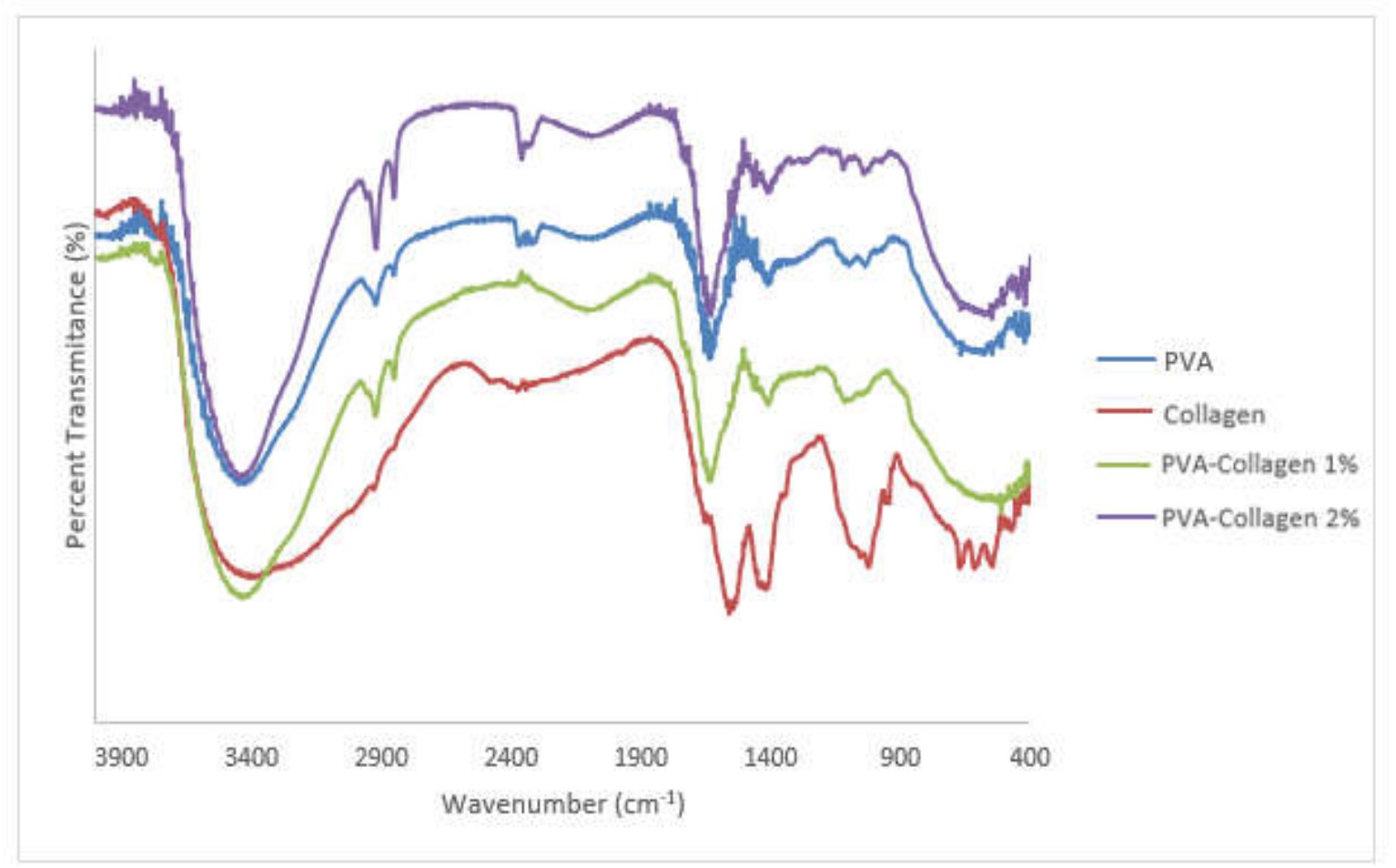

Fig. 1. FT-IR Spectrum of Nanofiber from PVA-Collagen

\subsection{Characteristics of Morphology}

Characteristics of SEM were performed to determine the distribution of collagen and PVA in collagen-PVA alloy fibers as well as to know the surface morphology. Collagen-PVA fibers formed from the electric spinning results can be seen in Figure 2.

Based on the figure, the resulting fiber has a thickness and uniformity of different fiber results. This may occur due to the less homogeneous solution, the flow rate of the solution in the electric spinning process is unstable, and the difference in voltage applied. Then we might perform an observation on the stereo microscope to find a clearer fiber surface. Based on observations using a microscope showed that the fibers formed cannot be seen from the difference in voltage variations and concentrations given as in Figure 3, so it is necessary to observe using SEM to determine the diameter, structure and morphology of fiber.

Furthermore, observations were made on samples using SEM with magnification 2000 times to determine the size of diameter, morphology and fiber structure. The diameter of PVA-collagen $1 \%$ wt and $2 \%$ wt fibers can be seen as in Figure 4. The drawings show that the fiber diameter size is influenced by the stress and 
concentration of the solution. The fiber size is decreased with the increasing of voltage applied. This is because the high voltage will create a strong electric field to draw the surface of the solution at the tip of the needle (spinneret) during the spinning process, so that the Taylor cone can form. The Taylor cone indicates the formation of the nanofibers, so that the fiber formed is is decreased with the increasing of applied voltage.

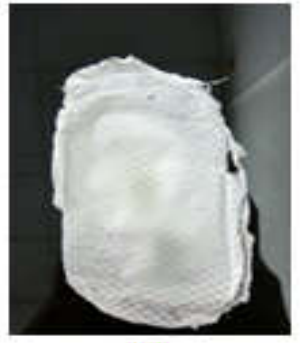

(a)

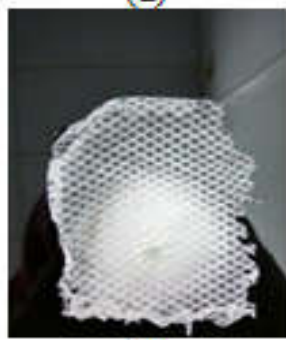

(d)

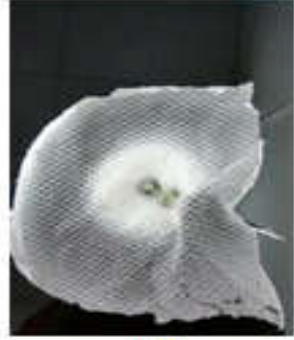

(b)

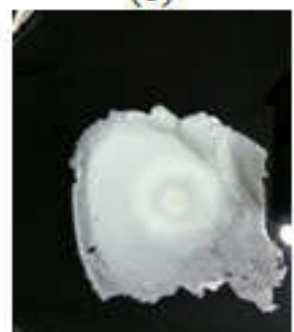

(e)

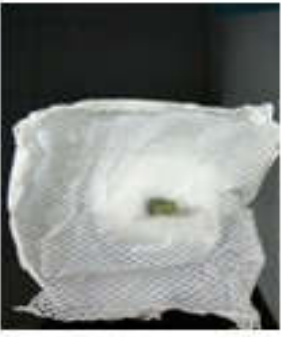

(c)

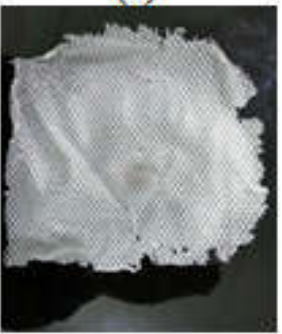

(f)

Fig. 2. Electrospinning fibers of PVA-Collagen $1 \% \mathrm{wt}$ (a) $15 \mathrm{kV}$; (b) $19 \mathrm{kV}$ (c) $23 \mathrm{kV}$; and PVACollagen $2 \%$ wt (d) $15 \mathrm{kV}$; (e) $19 \mathrm{kV}$; (f) $23 \mathrm{kV}$.

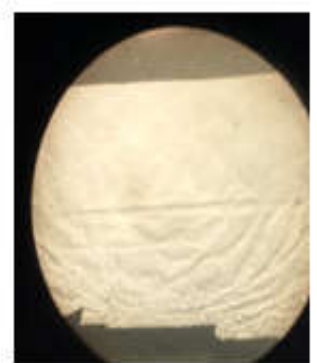

(a)

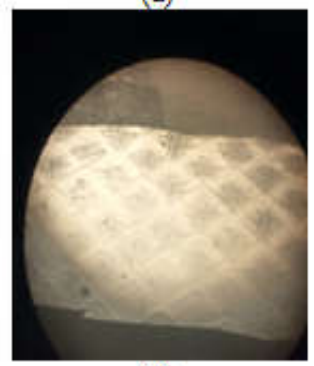

(d)

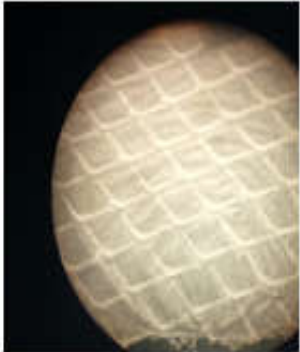

(b)

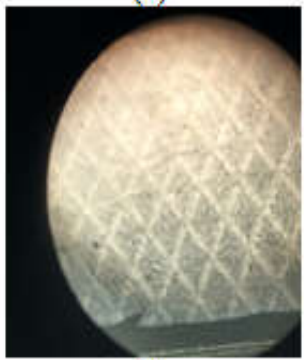

(e)

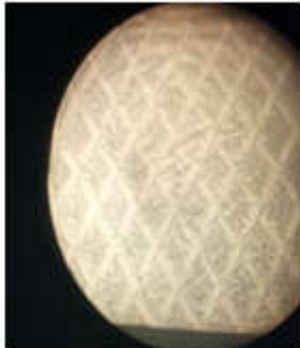

(c)

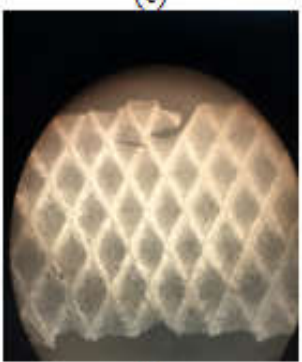

(f)

Fig. 3. From stereo microscope, the surface structure of PVA-Collagen $1 \%$ wt fibers on voltages (a) $15 \mathrm{kV}$; (b) $19 \mathrm{kV}$; (c) $23 \mathrm{kV}$, and PVA-Collagen $2 \%$ wt fibers on voltages (d) $15 \mathrm{kV}$; (e) $19 \mathrm{kV}$; (f) $23 \mathrm{kV}$ 


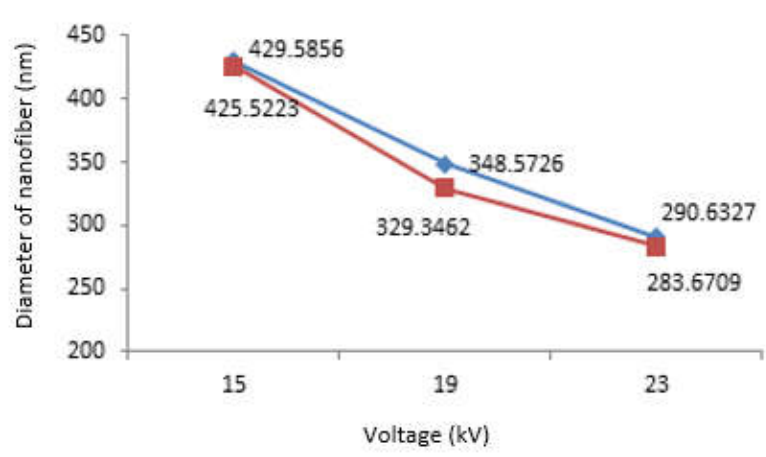

Fig. 4. The average diameter of PVA-Collagen fibers . $\rightarrow$ PVA-Collagen $1 \% \mathrm{wt},-$ PVACollagen $2 \mathrm{wt} \%$.

The concentration of the solution also affects the spinning process. Higher collagen concentrations cause difficult solutions to flow in the needle. This is due to the solvent that water undergoes evaporation. Thus, in the spinning process, the solution which should form the Taylor cone and move toward the collector to form the fibers will be dried and left behind at the tip of the needle and it is difficult to maintain a constant flow and inhibit the discharge from the tip of the needle. In addition, the surface tension on the fiber will affect the number of beads produced. Surface tension dominates the electric field Coulomb force in the emitted solution, so that the jet is not sufficiently stretched by the electric field. Another cause is that the solvent on the jet does not evaporate in large quantities, resulting in polymer droplets (beads) upon arrival in the collector [13].

Determination of average fiber diameter used ImageJ software. PVA-collagen fiber diameter was obtained by comparing the fiber diameter length with the scale in the SEM image. The average of fiber diameter could be calculated from 10 points as sample. The mean diameter values of PVA-collagen fibers are shown in Figure 7. Based on Figure 4, the largest diameter is produced on a PVA-collagen 1\%wt fiber with a voltage of $15 \mathrm{kV}$ that is equal to $429,5856 \mathrm{~nm}$ and the smallest diameter is produced on a PVAcollagen $2 \% \mathrm{wt}$ fiber with voltage $23 \mathrm{kV}$ that is equal to $283,6709 \mathrm{~nm}$. Good sizes of nanotubes used and traded are less than $500 \mathrm{~nm}$ in diameter or 50-300 $\mathrm{nm}$ in diameter [10]. In short, the most optimum size of PVA-collagen fiber after electric spinning process is at a concentration of $2 \%$ with a voltage of $23 \mathrm{kV}$.

During the electric spinning process, observations of variables have been observed, namely concentration of collagen solution (1\% and $2 \%)$ and stress $(15 \mathrm{kV}, 19 \mathrm{kV}$ and $23 \mathrm{kV})$ to the diameter, morphology and structure of the resulting fibers. The results of SEM test are shown in Figure 5. The SEM image shown in Figure $5(\mathrm{a}-\mathrm{c})$ is the electric spinning-generated fiber with $1 \%$ collagen concentration at a voltage of $15 \mathrm{kV}, 19 \mathrm{kV}$, and $23 \mathrm{kV}$ with magnification of 2000 time. The image shows that the fibers can be formed although it is not uniform yet and still many beads (polymer granules instead of fibers).

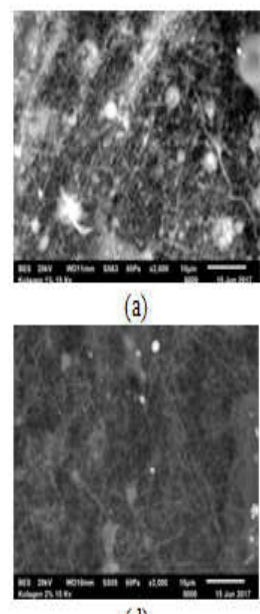

(d)

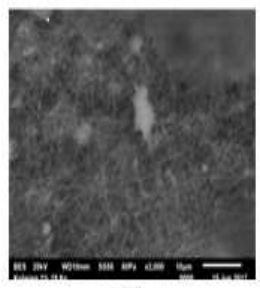

(b)

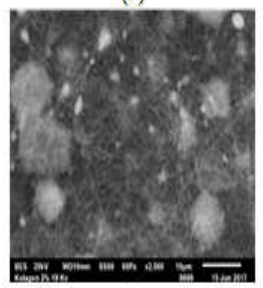

(e)

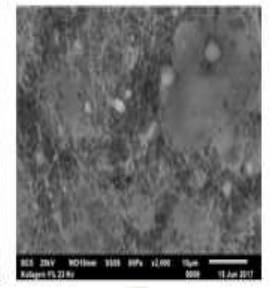

(c)

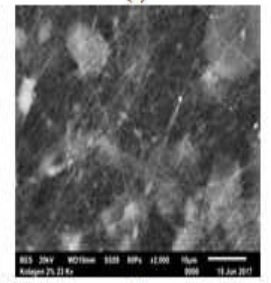

(f)
Fig. 5. SEM Images of PVA-Collagen $1 \% \mathrm{wt}$ fibers on voltages (a) $15 \mathrm{kV}$; (b) $19 \mathrm{kV}$; (c) $23 \mathrm{kV}$, and PVA-Collagen $2 \% w t$ fibers on voltages (d) $15 \mathrm{kV}$; (e) $19 \mathrm{kV}$;(f) $23 \mathrm{kV}$ with magnification of 2.000 time

These results show that the effect of low concentration of solution causes the polymer chain to be quite separate, the interaction between the polymers is minimized and the surface tension is stronger resulting in unstable fiber formation. The instability affects the size of 
the fiber diameter which is not uniform. Figure 5 (d-f) is a fiber produced electric spinning with a concentration of $2 \% \mathrm{wt}$ and a voltage of $15 \mathrm{kV}$, $19 \mathrm{kV}$, and $23 \mathrm{kV}$. The figure shows that the fibers formed are more uniform than the $1 \% \mathrm{wt}$ collagen concentration although there are still beads on the fibers.

\subsection{Analysis of X-Ray Diffraction}

X-ray diffraction method is one way to study the regularity of atoms or molecules in a particular structure. X-ray diffraction can provide polymer structure information that is amorphous state and crystalline polymer. Polymers may contain crystalline regions that are randomly mixed with amorphous regions. The XRD test can provide information on lattice parameters, approximate crystal size and comparison of crystalline regions with amorphous regions in the sample. In general, the polymeric material is semicrystalline having amorphous and crystalline parts. Both the amorphous and crystalline parts exhibit a specific scattering intensity [15].

Figure 6 (a) is a XRD pattern of PVA powder, Figure6 (b-c) is an XRD diffraction pattern formed from PVA-collagen fibers of electric spinning. The result of XRD analysis of PVA powder (Figure 6(a)) is at peak $2 \Theta 19.395$ ${ }^{\circ}$,PVA-collagen $1 \%$ wt fiber (Figure6(b)) shows that peak at $2 \Theta$ is $19.6171^{\circ}$, PVA-collagen $2 \%$ wt fiber (Figure6(c)) is at the peak of $2 \Theta$ $19.3509^{\circ}$. These results indicate that the PVAcollagen fibers of electric spinning have a crystalline peak does not change significantly [12]. The presence of collagen in the formed fibers results in wider peaks and decreases the intensity of the crystalline peaks compared to the powder of PVA powder without the addition of collagen.

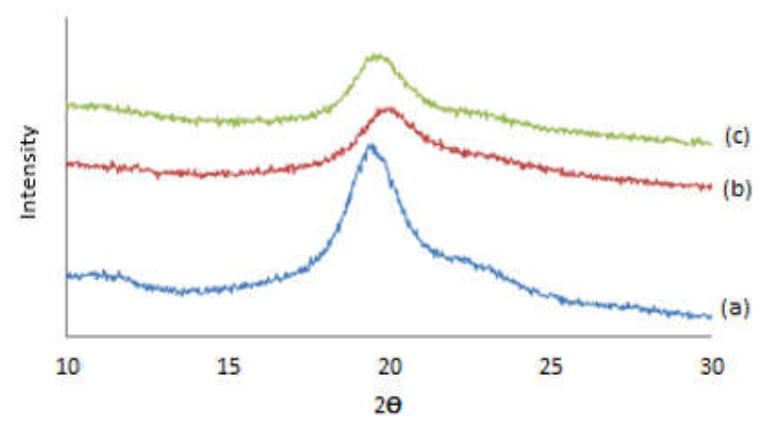

Fig. 6. XRD pattern of (a). PVA podwer, (b).PVA-Collagen $1 \%$ wt Fiber, (c). PVACollagen 2\%wt Fiber

\subsection{Analysis of Thickness}

The thickness of PVA-collagen fiber was measured using a digital screw micrometer with a precision of $0.001 \mathrm{~mm}$. This measurement is performed at 10 different points. Based on the results obtained, the average thickness of fiber is increased in PVA-Collagen $2 \%$ wt of the three variations of voltage given as in Figure 7 . It occurs due to the interaction of collagen and PVA are not uniform. Additionally, the jet solution dries up during the electric spinning process so that the fibers cannot form.

Based on the thickness value, PVA-Collagen $2 \%$ wt fibers with a voltage of $15 \mathrm{kV}$ has the highest thickness value of $0.0483 \mathrm{~mm}$ and PVAcollagen $1 \% \mathrm{wt}$ fiber with $23 \mathrm{kV}$ voltage has the lowest thickness value of $0.0282 \mathrm{~mm}$. PVACollagen $2 \% \mathrm{wt}$ fiber with a voltage of $15 \mathrm{kV}$ are the best for wound dressing because the thicker the membrane fibers can absorb the active substances that play an important role in wound healing [17]. 
pp. $55-65$, April 2020

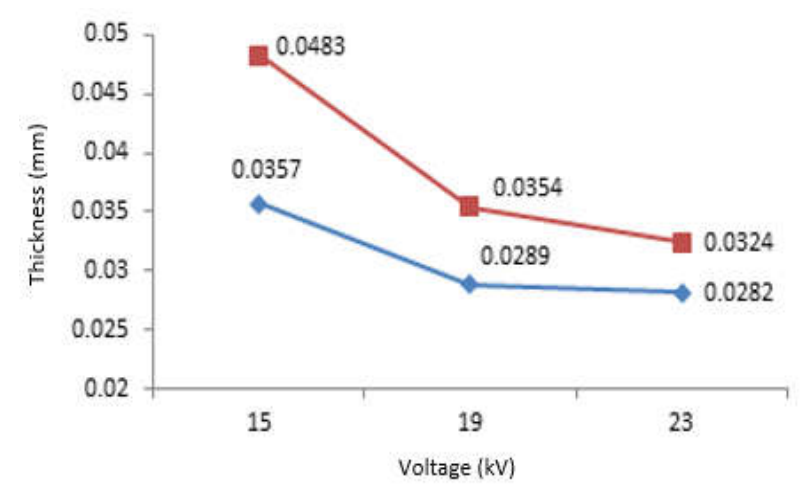

Fig. 7. The thickness average of PVA-Collagen $\rightarrow 1 \%$ wt fiber, $-2 \%$ wt fiber.

\subsection{Analysis of Mechanical Properties}

The analysis of the mechanical properties of PVA-collagen fibers from electric spinning using tensile testing instruments obtained a value of tensile strength and percent elongation. The value of tensile strength indicates the maximum force used to decide the membrane and percent elongation indicates the ability of the membrane to stretch due to the applied tensile force. The mechanical properties of a material relate to its molecular structure. The molecular structure that influences the mechanical properties of a material includes molecular form, molecular compactness, crystallinity, molecular bond strength and intermolecular forces [18].

The elongation value is decreased due to the decreasing of tensile strength value. The highest elongation rate was found in PVA-collagen 2 $\%$ wt fibers of $29.3 \%$, while the lowest percentage of elongation in PVA-collagen $1 \% \mathrm{wt}$ fibers is $14.3 \%$.

Addition of PVA polymer may affect to percent elongation. The percent value of elongation increased with the increasing of collagen concentration in the mixture of PVAcollagen. According to standard of medical material, elongation value between 17-207\%, and value of tensile strength between 1-24 MPa [15]. Based on the results of elongation percentage and the value of its tensile strength, a
PVA-collagen $2 \%$ wt fiber is best used as a wound dressing because it has the highest elongation value and a tensile strength value that lies within the range of medical standards. Wound dressings should have a high percentage of elongation to prevent breakage of pads when used to cover wounds [20].

Table 1. Tensile test results of PVA-Collagen fibers on $19 \mathrm{kV}$

\begin{tabular}{cccc}
\hline Sample Name & $\begin{array}{c}\text { Thickness } \\
(\mathrm{mm})\end{array}$ & $\begin{array}{c}\text { Tensile } \\
\text { Strength } \\
(\mathrm{MPa})\end{array}$ & $\begin{array}{c}\text { Elongation } \\
(\%)\end{array}$ \\
\hline $\begin{array}{c}\text { PVA- } \\
\text { Collagen } \\
\text { 1\%wt }\end{array}$ & 0.0289 & 1.73 & 14.3 \\
$\begin{array}{c}\text { PVA- } \\
\text { Collagen } \\
\text { 2\%wt }\end{array}$ & 0.0354 & 1.41 & \\
\hline
\end{tabular}

\section{CONCLUSION}

The synthesis of PVA-collagen fibers can be conducted by electric spinning method by giving two variations namely variation of concentration of collagen solution of $1 \%$ and $2 \%$ and variation of voltage equal to $15 \mathrm{kV}, 19 \mathrm{kV}$, and $23 \mathrm{kV}$. The effect of collagen concentration varation given on PVA-collagen fibers results in widening crystal peaks and decreases the intensity of crystalline peaks. The results of PVA-collagen fiber infrared uptake indicate the presence of a compound identical to the PVA or collagen spectrum and there is no formation of new functional groups. The effect of increasing stresses can form fibers of smaller size and thinner. The effect of increasing the concentration of the collagen solution can decrease the wave number in the functional group formed, decrease the average diameter of the fiber, increase the fiber thickness, decrease the tensile strength value and increase the 
percentage elongation. The result of $2 \%$ PVAcollagen fiber is the best as wound dressing material that has a thickness of about 0.0324$0.0483 \mathrm{~mm}$, a small diameter of about 283-425 $\mathrm{nm}$, and has a tensile strength value of $1.41 \mathrm{MPa}$ and elongation percentage of $29.3 \%$ with standard medical materials.

\section{REFERENCES}

[1]. M. Mirjalili, S. Zohoori. "Review for application of electrospinning and electrospun nanofibers technology in textile industry", Journal of Nanostructure in Chemistry, vol. 6, pp. 207-213, 2016.

[2]. M. Liu, X. P. Duan, Y. M. Li, D. P. Yang, Y. Z. Long. "Electrospun nanofibers for wound healing", Materials Science and Engineering: C., vol. 76, pp. 1413-1423, 2017.

[3]. E. D. Kotler, W. S. Marshall, E. G. Gareta. "Sources of collagen for biomaterials in skin wound healing", Bioengineering,vol. 6, no. 3, pp. 56, 2019.

[4]. A. Ika, Nurjanah, T. Nurhayati. "Karakteristik kolagen larut asam dari kulit ikan ekor kuning", Perikanan Hasil Perairan Indonesia. Vol. 19, no. 1, pp. 7993, 2016.

[5]. M. Erencia, F. Cano, J. A. Tornero, M. M. Fernandes, T. Tzanov, J. Macanas, F. Carrillo. "Electrospinning of gelatin fibers using solutions with low acetic acid concentration : Effect of solvent composition on both diameter of electrospun fibers and cytotoxicity", Journal of Applied Polymer Science, vol. 132, no. 25, pp 42115, 2015.

[6]. P. Zou, W. H. Lee, Z. Gao, D. Qin, Y. Wang, J. Liu, T. Sun, Y. Gao. "Wound dressing from polyvinyl alcohol/chitosan electrospun fiber membrane loaded with OH-CATH30 nanoparticles",
Carbohydrate Polymers, vol. 232, pp. 115786, 2019.

[7]. N. Dwi, S. E. Budi, P. A. Tri. "Sintesis membran kitosan-pva terikat silang untuk menurunkan kadar zat warna remazol red", Indonesian Journal of Chemical Science, vol. 1, pp. 28-35, 2014.

[8]. F. E. Ahmed, B. S. Lalia, R. Hashaikeh. "A review on electrospinning for membrane fabrication : Challenges and applications", Desalination, vol. 356, pp. 15-30, 2015.

[9]. W. Liang, J. Hou, X. Fang, F. Bai, T. Zhu, F. Gao, C. Wei, X. Mo, M. Lang. "Synthesis of cellulose diacetate based copolymer electrospun nanofibers for tissue scaffold", Applied Surface Science, vol.443, pp. 374-381, 2018.

[10]. Sai KP, Babu M. "Studies on Rana tigerina skin collagen", Biochemistry and Physiology Part B: Biochemistry and Molecular Biology. vol.128, no.1, pp. 8190, 2001

[11]. H. Yang, S. Yang, J. Kong, A. Dong, S. $\mathrm{Yu}$. "Obtaining information about protein secondary structure in aqueous solution using Fourier transform IR spectroscopy", Nature Protocols, vol. 10, no. 3, pp. 382396, 2015.

[12]. S. Chen, B. Liu, M. A. Carlson, A. F. Gombart, D. A. Reilly, J. Xie. "Recent advances in electrospun nanofibers for wound healing", Nanomedicine,vol. 12, pp. 11, 2017.

[13]. H. Herlan, Juliandri, Nasir M. "Pembuatan dan karakterisasi Co-PVDF nanofiber komposit dengan menggunakan metode elektrospinning", Jurnal BATA. 2013.

[14]. D. Fadhila. "Prarancangan pabrik polivinil alkohol dari vinil asetat monomer dan metanol dengan kapasitas 30.000 ton/tahun" [skripsi]. Yogyakarta (ID): Universitas Gadjah Mada. 2014.

64 | "Synthesis of Nanofiber from Poly Vinil Alcohol (PVA) Collagen ...": Sudirman, et.al. 
pp. $55-65$, April 2020

[15]. C. I.C. Crucho, M. T. Barros. "Polymeric nanoparticles: A study on the preparation variables and characterization methods", Materials Science and Engineering : C., vol. 80, pp. 771-784, 2017.

[16]. K. R. Aadil, A. Nathani, C. S. Sharma, N. Lenka, P. Gupta. "Fabrication of biocomposite alginate-poly(binyl alcohol) nanofibers scaffolds for tissue engineering applications", Materials Technology : Advanced Performance Materials.vol. 33, pp. 507-512, 2018.

[17]. A. A. Aldana, G. A. Abraham. "Current advances in electrospun gelatin-based scaffolds for tissue engineering applications", International Journal of Pharmaceutics,vol. 523, pp. 441-453, 2017.

[18]. A.M. Abd El-aziz, A. El-Maghraby, N. A. Taha. "Comparing between polyvinyl alcohol (PVA) nanofiber and polyvinyl alcohol (PVA) nanofiber/Hydroxyapatite (HA) for removal of $\mathrm{Zn}^{+2}$ inos from waste water", Arabian Journal of Chemistry, vol. 10, pp.1052-1060, 2017.

[19]. Meilanny D K P, Pranjono B E, Dyah H. "Metode elektrospining untuk mensintesis komposit berbasis alginate-polivinil alcohol dengan penambahan lender bekicot" Jurnal Electrospinning Universitas Airlangga,pp. 65-71, 2015.

[20]. S. H. Xia, S. H. Teng, P. Wang. "Synthesis of bioactive polyvinyl alcohol/silica hybrid fibers for bone regenration", Materials Letter,vol. 213, pp. 181-184, 2018. 